\title{
ARTE CONCEITUAL E HISTÓRIA: Desafios da construção poética na década de 1970
}

CONCEPTUAL ART AND HISTORY: Challenges of poetic

Rodrigo Vivas ${ }^{1}$ 


\section{Resumo}

A década de 1970 significou um momento de grande complexidade por comportar, de um lado, perseguições, torturas e cerceamento da liberdade, e de outro, um espaço de contínua efervescência artística. Infelizmente as pesquisas têm concentrado maior interesse em discussões no campo da música e do teatro, conferindo pouca dedicação às artes visuais. No presente artigo serão analisadas algumas questões artísticas desenvolvidas no período, tendo como eixo as premiações, críticas e obras dos Salões de Arte da Prefeitura de Belo Horizonte. Para tanto, serão contemplados os trabalhos de Miguel Gontijo.

Palavras-chave: vanguarda, arte conceitual, arte contemporânea, museu.

\section{Abstract}

The Brazilian's 70's was a period filled with complexity: in one hand there was the dictatorship, with persecutions, torture and lack of freedom, and on the other hand, there was an increasing in the art movement. Unfortunately, most researches are focused in the discussions of music and theater fields and few studies worked with visual arts. At the present work, artistic features developed in the 70's will be analysed, taking into account awards, critics and works of the Art Saloons promoted by the city council of Belo Horizonte (Salões de Arte da Prefeitura de Belo Horizonte, in Portuguese) as a baseline. The art work of Miguel Gontijo will be contemplated.

Keywords: vanguard, conceptual art, contemporary art, museum.

ISSN: 2175-2346

1rodvivas@gmail.com 


\section{Introdução}

No Brasil, a produção no campo das artes visuais atravessou um período profícuo de experimentações, ações e expansão na década de 1960. As tradicionais divisões das categorias artísticas como pintura, escultura, desenho e gravura foram questionadas, levando a uma ampliação do espaço artístico. Em quase uma década, grande parte das transformações ocorridas no campo das artes visuais - proporcionadas pelas vanguardas europeias - parecem ter sido vivenciadas na capital mineira: passagem da arte figurativa à abstrata, utilização de materiais não convencionais para a prática artística, processos de desmaterialização, entre outros. Nas palavras de Paulo Sérgio Duarte

Às tradicionais práticas pictórica, escultórica e gráfica somam-se as experiências fotográficas, filmográficas, videográficas, cenográficas, performáticas, e até práticas puramente teóricas, umas fundamentadas em questões lógicas e linguísticas, outras em sociologia do conhecimento artístico e crítica institucional (DUARTE, 2005, p. 137).

Em mesmo sentido, essas questões foram abordadas nos Salões de Arte da Prefeitura de Belo Horizonte ao contarem com a participação de parte significativa de artistas atuantes no circuito nacional. Os Salões de Arte configuraram-se como um dos poucos mecanismos institucionais de validação artística, apenas comparados às Bienais de São Paulo. A diferença residia na participação de artistas ainda não consagrados no circuito, mas eles também contavam com nomes reconhecidos. A análise da lista de artistas que figuraram nos Salões de Belo Horizonte confirma a inferência anterior: Amilcar de Castro, Franz Weissmann, Flávio Shiró, Angelo Aquino, Frederico Morais, Ivan Serpa, Burle Marx, Rubem Valentim, Antonio Henrique Amaral, Anna Letícia Quadros, Marcos Coelho Benjamin, Maria Bonomi, João Câmara, apenas para citar alguns.

Apesar da relevância, não com pouca frequência, o evento esteve associado à ideia de crise, sucedida por momentos de ressignificação, que, contudo, acabavam por não alterar a estrutura original do evento, onde um júri - anualmente modificado - era responsável pela escolha dos expositores e premiação dos concorrentes. Independentemente da legitimidade da proposta, é necessário registrar sua capacidade em colocar em debate os critérios, as preferências e principalmente o exercício da crítica de arte e a discussão pública. Atualmente, muitos sistemas de seleção mantêm o programa de escolhas, mas não seu sistema de seleção, o que nos deixa cegos em relação aos critérios adotados pelas comissões julgadoras, eliminando a possibilidade de um debate aberto.[A3] Nesse sentido, os Salões nunca foram de Minas Gerais ou Belo Horizonte, mas realizados e patrocinados pelo município. Assim como as Bienais de Veneza não pertencem apenas à Veneza ou as Bienais de São Paulo se restringem ao estado.

Um outro dado importante se refere à circulação de artistas e comissões julgadoras em salões distribuídos pelo país. Como nos informa Emerson Dionísio Gomes de Oliveira, em relação aos anos 60 , 
Embora os "artistas" predominem na listagem, os nomes que mais recorreram estavam posicionados como críticos e estiveram indissociavelmente presentes nos mais importantes salões do período. São eles: José Geraldo Vieira (12 eventos), Mario Schenberg, Frederico Morais e Walter Zanini (11 eventos), Mário Pedrosa (9), Jayme Maurício (8 eventos), Geraldo Ferraz e Quirino Campofiorito (7) (OLIVEIRA, 2011, p. 482).

Mas esse horizonte tão singular da década de 1960 se mantém efervescente na década de 1970? Quais os impactos do regime de exceção que atravessou o Brasil? Como os artistas responderam ao cenário político da década de 1970? Qual a noção de política pode ser pensada dentro desse sistema? É necessário considerar que muitas vezes a análise do período é generalizada quanto à questão da militância em áreas como a música e o teatro, mas pouco destaque se tem dado às artes visuais ${ }^{1}$. Essa argumentação pode ser encontrada em Artur Freitas ao afirmar que

as artes plásticas, por seu lado, deram um encaminhamento bastante específico a essas questões, um encaminhamento em geral, diferente daqueles realizados pelas outras áreas de expressão artística - e por diversas razões. (FREITAS, 2004, p. 71)

Uma das questões é que o engajamento político explícito "não era recorrente nas obras dos artistas plásticos, mesmo nos momentos mais duros da repressão." (FREITAS, 2004, p. 71).

Marcelo Ridenti realiza um dos estudos inaugurais sobre a temática ao quantificar os dados dos "Setores da esquerda brasileira, por ocupação e grupos ocupacionais de processados, 1964 - 1974" (RIDENTI, 1993, p. 73). Neste trabalho, ele nos revela que apenas 0,9\% dos 1897 membros de grupos armados urbanos eram artistas visuais, ou seja, um número que não ultrapassa 18 pessoas. Entretanto, é importante registrar que essa é uma verificação numérica com base em processos judiciais, não nos permitindo saber, portanto, quais foram os critérios e as atividades específicas ligadas às artes para definição deste número de profissionais. Mas em certa medida, não deixa de confirmar o que Ridenti aponta, "vários artistas e intelectuais no período tinham uma simpatia difusa pela esquerda armada, sem que seja possível dizer que eram propriamente militantes" (RIDENTI, 2000, p. 180).

Com base nas premissas expostas, o presente trabalho se volta à compreensão das temáticas e discussões que movimentaram a década de 1970 através de um levantamento das obras premiadas nos Salões de Arte de Belo Horizonte. O objetivo é identificar as estratégias formuladas pelos artistas além de uma possível noção de política.

Algumas temáticas atravessaram a década de 1970 e podem ser distribuídas nos seguintes pontos: 1) Conceitual/Processual e os novos meios, que problematizaremos do ponto de vista do levantamento do debate; 2) História: ficção e reinvenção, a partir da análise da obra de Miguel Gontijo.

\footnotetext{
1 Para uma discussão mais aprofundada sobre o tema conferir: SANTOS, Nelyane; VIVAS, Rodrigo. Questionamentos sobre as relações de condicionalidade entre proposições artísticas e o contexto político do Brasil na década de 1960 nas obras dos Salões Municipais de Belas Artes da Prefeitura de Belo Horizonte. Anais eletrônico do Seminário 1964-2014 : um olhar crítico, para não esquecer [recurso eletrônico] / Organizado por Rodrigo Patto Sá Motta, Miriam Hermeto Sá Motta,Gabriel Amato Bruno de Lima . - Belo Horizonte :Faculdade de Filosofia e Ciências Humanas, 2014.
} 


\section{Conceitual/Processual e os novos meios}

Um cenário de desconstrução parece ter chegado ao limite principalmente após a década de 1960, quando artistas passaram a enviar "propostas", "projetos" e dispositivos para a concorrência das premiações. Esses desafios foram colocados ao Museu de Arte da Pampulha e aos membros do júri - de forma efetiva, na edição de número V dos Salões Nacionais de Arte, em 1973.

Esse problema já fora abordado na década de 1960, mas no momento se transformou em pauta para a crítica de arte e artistas. O conceito de "obra artística" passava por transformações. Até então, o artista oferecia um trabalho acabado materialmente, a partir de uma técnica e modalidade artística, pertencendo à pintura, escultura, desenho ou gravura. No entanto, na referida década, estas definições de categorias artísticas passaram por inúmeras modificações, produzindo a necessidade de novas terminologias.

Objetos, relevos, instalações foram nomes elaborados para abarcar as novas possibilidades oferecidas pelos artistas.

As manifestações artísticas se estendem desde a arte conceitual, performances, arte postal até novas investigações no campo da escultura e da pintura. O laboratório das transformações dos anos 70 é responsável por uma mudança profunda no regime de percepção do meio de arte no mundo e, particularmente, no Brasil, no qual o pequeno público e mesmo boa parte dos críticos se encontravam ainda presos às convenções "belasartianas". (DUARTE, 2005, p. 138).

Diante destas novas perspectivas, qual seria o destino de um Salão, cuja função, entre outras, era o acolhimento de obras que fariam parte da coleção de um dos museus mais relevantes nas artes visuais de Minas Gerais? Com o início das produções contemporâneas, como premiar "projetos" ou "processos", se o Museu não tinha conseguido sequer se estruturar para mostrar sua coleção reunida desde a década de 1950?² Como se sabe, os Salões de Arte da Prefeitura foram grandes responsáveis pela constituição do acervo da instituição. Salão após Salão, obras eram incorporadas ao museu a partir do prêmio de aquisição ${ }^{3}$.

Vale destacar que as obras produzidas a partir dos novos meios também exigiam novos equipamentos para sua apresentação. Para além de problemas técnicos de instalação e preservação, ainda temos a discussão do referido conceito de "obra artística" como única e não reprodutível, assim como a noção de "projeto". Muitos deles possuíam um orçamento previsto que poderia ultrapassar o valor destinado à premiação. Deveria, então, o júri investir nessa proposta? Ora, um projeto de arte a ser executado não pode ser mensurado monetariamente de forma tão precisa, podendo surgir contratempos e despesas imprevistas. Ou seja, o valor pago na premiação talvez não fosse suficiente para a execução do planejado. Além disso, é impossível prever um resultado final.

2 Para uma abordagem mais detalhada do assunto consultar: VIVAS, Rodrigo; GUEDES, Gisele. Desejos individuais - imagens de coletividade. ouvirouver, Uberlândia v. 12 n. 1 p. 168 -1 79 jan.| jul. 2016. Disponível em: <http://www.seer.ufu.br/index.php/ouvirouver/article/view/31216>. Acessado em 14 de dezembro de 2016.

30 prêmio de aquisição consistia na reserva de uma verba feita pela Prefeitura destinada à premiação de artistas concorrentes, escolhidos pelo júri. O artista premiado recebia a remuneração e sua obra era incorporada à coleção do museu. O Salão de 1977 é um exemplo do colecionismo, tendo premiado 32 artistas com a aquisição de suas obras. 
Mas o que estava em jogo nesse debate? O que significava premiar uma obra com a utilização dos novos meios ou uma proposta "conceitual" ou "processual"? O modelo inicial das Belas Artes comportava um critério de seleção que trazia em seu escopo as diferenças entre objetos "comuns" e objetos de arte, caso um Museu passasse a comportar objetos do mundo sem critério, a instituição perderia sua função. O problema é que tanto os novos meios como também as propostas conceituais se transformaram em chancela para a definição da arte contemporânea. Criou-se a sensação equivocada de que existiria uma substituição das técnicas. Assim como um $C D$ substituiu um disquete, o diapositivo substituiria a pintura ou a gravura. No que se refere aos critérios, muitos artistas passaram a utilizar os novos meios, pensando que apenas a sua utilização garantiria o acesso ao título de obra de arte contemporânea.

Podemos afirmar que as propostas conceituais tinham como referência uma resposta ao regime militar? Buscar a construção de uma ideia poderia ser uma forma mais efetiva de elaborar um discurso de denúncia? Com relação a esse posicionamento é possível elencar o trabalho de Freitas:

Como, eventualmente, a vanguarda brasileira reagiu - em termos estéticos e ideológicos - perante as contradições culturais dos primeiros anos do AI-5? [...] como constatação mais genérica, procurei desenvolver ao longo do livro a ideia de que não é ausente de sentidos históricos a notável coincidência cronológica que existe entre os primeiros anos de vigência do AI-5 e o surgimento de uma produção artística dita "conceitual" ou, como prefiro, "conceitualista" (c. 1969 - 1973) (FREITAS, 2013, p. 23).

Convém esclarecer que Artur Freitas selecionou em seu livro um conjunto de artistas que responderam diretamente às questões, mas não podemos generalizar todo o circuito estabelecendo vínculos diretos entre produções conceituais e Al-5.

Como nos alerta Paulo Sergio Duarte:

Como o Brasil vivia sob o regime da ditadura militar durante os anos 70 , a primeira tentação não-especialista é vincular o campo político ao artístico e procurar as interações recíprocas, às vezes determinações mecânicas do primeiro sobre o segundo, na busca dessas características. As coisas não são tão simples. Aprendemos que o campo estético goza de uma autonomia relativa diante das instâncias políticas, econômicas e sociais. (DUARTE, 2005, p.134).

No que se refere ao Salão de Arte de Belo Horizonte, a discussão pode ser dividida em dois posicionamentos: o primeiro era adotado por partidários dos que eram considerados "fundamentalmente ligados às tendências da arte de hoje" (ALVIM, 1973, s/p), o que envolve o acolhimento por parte do museu de todas as novas possibilidades artísticas: audiovisuais, diapositivos, projetos artísticos, performances $e$ artes conceituais em geral. A segunda postura englobava o grupo resistente à premiação das novas modalidades artísticas, tendo em vista o contexto de um museu regional que não conseguia preservar e principalmente mostrar o acervo constituído. Sendo assim, o júri do V Salão, coordenado por Conceição Piló ${ }^{4}$, composto pelo embaixador Fernando Simas Magalhães ${ }^{5}$, José Joaquim Carneiro de Mendonça ${ }^{6}$ e 
Walmir Ayala ${ }^{7}$, preferiu premiar artistas que já eram consolidados no circuito artístico, o que facilitaria a inserção de suas obras no contexto museológico.

Além disso, tratava-se de um investimento, pois seria inquestionável premiar artistas já renomados, unânimes no juízo crítico, contribuindo significativamente na formação da coleção do Museu de Arte da Pampulha. Entre os 12 contemplados com o prêmio de aquisição figuravam novos artistas, "mais ou menos conhecidos, mas todos portadores de novos timbres de linguagem" (AYALA, 1973, s/p.). Ayala manteve uma postura cautelosa ao ponderar sobre "novos timbres", sendo que, na verdade, as categorias continuavam as mesmas: pintura, escultura, gravura e desenho.

Contrariando a defesa de Ayala às premiações, Celma Alvim ${ }^{8}$ questionou os critérios adotados pelo júri, e defendeu, em publicação no jornal Estado de Minas, que o Salão deveria mostrar obras em maior consonância com o que seria "moderno" nas artes visuais. Deste modo, para Alvim, "nem todos estavam suficientemente equipados, em termos de informação e vivência, a serem juízes de um Salão supostamente de arte moderna" (ALVIM, 1973, s/p). Alvim trata como fundamental premiar os representantes das "tendências da arte de hoje". Para além das reivindicações em apoio às "novas expressões artísticas", Celma Alvim ainda criticou a não premiação ao desenho de Manoel Serpa e as escolhas de Grassmann e Burle Max pela alegação de serem "inteiramente desprovidos do traço inovador que justificaria sua presença num Salão/Documentário da arte de hoje." (ALVIM, 1973, s/p).

Alvim reitera a discrepância entre as novidades buscadas por alguns artistas, enquanto outros continuavam insistindo em suas fórmulas usuais.

O panorama geral das obras em exposição revela uma flagrante dualidade: de um lado, a surpreendente presença de artistas há muito desvinculados dos certames de ordem competitiva, gente que se fez importante e inédita em décadas passadas; do outro, a representação atual e atuante de artistas fundamentalmente ligados às tendências da arte de hoje. (ALVIM, 1973, s/p).

Morgan Mota foi outro crítico que se posicionou sobre as premiações deste Salão. Em sua opinião o critério adotado foi muito conservador, premiando "medalhões" e recusando muitas propostas inovadoras. Segundo Mota,

as propostas atuais: conceituais, fotografias, ambientais, performances e audio-visuais (sic) - várias delas excelentes - foram apenas selecionadas e nem atribuíram uma verba para documentação como ocorreu nos três últimos salões (MOTA, 1973, s/p) .

Para Mota, era contraditório premiar artistas "parados no tempo" enquanto se recusava jovens com novas propostas. Talvez Mota - que concorria com um audiovisual neste Salão - não concordasse com a missão do Museu da Pampulha, que

7 Crítico de arte. De 1968 a 1974, escreveu uma coluna sobre crítica de arte. Viajou à Itália, ao Chile e ao Paraguai em missão cultural do Ministério das Relações Exteriores e representou o Brasil nas bienais internacionais de Veneza e Paris. Em 1965 organizou a exposição de José Pancetti no Rio de Janeiro, no mesmo ano participa do júri de seleção do Resumo de arte JB, no MAM do Rio. Em 68 participou do júri do Salão Municipal de Belas Artes de Belo Horizonte. Em 69 foi jurado no Salão Nacional de Arte Moderna no Rio de Janeiro. Ainda em 69 participou, também como jurado, da Bienal de S. Paulo. Neste ano cumpriu a mesma função no Salão da Bússola no MAM do Rio de Janeiro. Disponivel em: <http://enciclopedia.itaucultural.org.br/pessoa66/walmir-ayala>. Acesso em 05 de dezembro de 2016. 8 Celma Alvim surgiu no cenário artístico ainda na década de 1960 escrevendo principalmente sobre os Salões de Arte de Belo Horizonte. Foi jurada, em 1970 do Salão da Cultura Francesa e no Salão de Arte Nacional Contemporânea, em Belo Horizonte, em 1973 foi jurada na Bienal Internacional de São Paulo, e nos Salões Nacionais de Arte de Belo Horizonte, em 1977, 1980 e 1981. Disponivel em: http://enciclopedia.itaucultural.org.br/pessoa11552/celma-alvim (Acessado em 21/02/2017). 
não foi criado em um local construído com intenção de receber esta instituição, não possuindo, assim, local apropriado para preservação e exposição, seus fins primeiros. É curioso notar, entretanto, que em 1970, o mesmo Mota faz uma oposição ferrenha à apresentação de um audiovisual inscrito no Salão daquele ano:

Muito engraçado também foi o critério da gravura tradicional aos trabalhos conceituais como "A nova crítica" de Frederico Morais, que supriu a ausência do $1^{\circ}$ time da vanguarda. Seu trabalho nada mais é do que o registro (filmes e "slides") de manifestações vanguardistas no Rio, São Paulo e inclusive "Do Corpo à Terra", realizada aqui em Belo Horizonte, no Palácio das Artes. O trabalho é importante, mas, convenhamos, um museu como o nosso que não consegue conservar nem as obras que fazem parte do seu acervo. Já pensaram onde vão parar os "slides" e filmes que compõem o trabalho do crítico-artista? É muita pretensão registrar e, ainda mais, premiar trabalhos conceituais. É possível nos Estados Unidos ou Europa, onde há pessoa para cuidar disso tudo, como há restauradores nos museus de fato. (MOTA, 1970, s/p).

A dubiedade de opiniões do crítico Morgan Mota sobre o audiovisual se choca com a política do acervo do Museu. Ao apresentar, três anos depois, um audiovisual, defendendo sua relevância para aquisição, caberia talvez interpretar que Mota teria mudado seus conceitos desde a discussão de 1970, ou suas opiniões a respeito da proposta de Frederico Morais foram fundamentadas na intenção pessoal, tendo em vista os embates entre os críticos desde 1967.

Ayala, entretanto, não concordou com as novas fórmulas adotadas tanto pela arte conceitual, o audiovisual ou outras possibilidades técnicas. O problema decorreu do termo "contemporâneo" referir-se ao recurso técnico e não propriamente ao resultado expressivo. Na argumentação de Ayala,

Muitas vezes, o abuso da facilidade aparente do conceitual (uma categoria que independe de disciplina e técnica) tem levado os jovens a manipularem ingenuamente um arremedo de comunicação, esquecidos da alta missão da arte, com qualquer instrumento, qual seja a de recriar as circunstâncias do existencial, de forma a transferí-las para um plano universal. (AYALA, 1973, s/p.)

Como representante dos artistas, Terezinha Soares ${ }^{9}$, jovem integrante do circuito de arte nacional, fez uma reflexão sobre as decisões do júri. Na ocasião, debateu sobre as admissões, questionou o regulamento e enfatizou a necessidade de mudanças.

Em seu texto "O Circo e a Montanha", mesmo título do trabalho com o qual concorreu no Salão, Soares justifica sua obra proposta comparando a lona do circo e a montanha de maneira irônica. Faz uma paródia da cidade, questiona a vida nos grandes centros, as disparidades sociais, o problema do transporte e associa o verde das montanhas com a lona do circo. Simbolicamente, a cidade seria o próprio circo onde desempenhamos o papel de malabaristas e palhaços. Nas palavras da artista,

Tudo é válido, no nosso palco. Uma vez que, quem faz o espetáculo é o homem. Animal peculiar, racional, sensível, político e capaz de errar. Que é o júri? - Um composto de três elementos; três cabeças, três maneiras de olhar as coisas, três sentenças. O que é resultado? - A soma, a divisão ou a barganha de opiniões. $\mathrm{O}$

9 Pintora, gravadora e desenhista. Participou, além de Salões de Arte em Belo Horizonte, do Salão das Caixas, no Rio de Janeiro, da Bienal de S. Paulo, do Salão de Arte Contemporânea de Campinas e do Salão de Arte Moderna de Brasília, todos em 1967. Em 1968 participou da exposição "O Artista Brasileiro e a Iconografia de Massa" no Rio de Janeiro e do Salão de Arte Contemporânea de Campinas. 
que é regulamento? - Aquilo que precisa ser mudado urgentemente, se o salão pretende significar Salão de Arte Moderna. Pois um dos seus itens estabelece que os prêmios serão de aquisição. Como pendurar na parede uma proposta? Por que comprar um audiovisual se o museu não dispõe de projetor? Que fazer de uma idéia(sic), pesquisa? (SOARES, Terezinha, 1973, s/p.)

O júri para a seleção das obras participantes e escolha das premiações no IX Salão, em 1977, era composto por Celma Alvim, Mari'Stella Tristão ${ }^{10}$ e Jayme Maurício ${ }^{11}$ e o mesmo debate é retomado por Jayme Maurício, em texto publicado no catálogo do evento. Maurício, para sustentar sua argumentação, baseia-se na definição de "obra aberta" de Umberto Eco para contextualizar os audiovisuais, performances e processos. Mas reconhece uma crise geral da arte, após a "sacralização da tecnologia, da cibernética e das histerias estruturalistas que quase destruiriam o humanismo para o diálogo interplanetário." (MAURíCIO, 1977, s/p)

Maurício questiona a associação direta entre uso da tecnologia e a produção artística contemporânea. Assim, parece que a intenção do júri no Salão de 1977 era de rediscutir os critérios e não aceitar propostas apenas pela "novidade" na utilização dos novos meios. Em sua coluna no Estado de Minas, Mari'Stella Tristão, como já mencionado, jurada naquele evento, ressalta o reflexo de "tempos de mudança" no comportamento do Salão onde "o esvaziamento dos salões nacionais e internacionais tem seu reflexo no salão mineiro, apesar de todo o esforço da Prefeitura e do Museu" e, mesmo assim, para ela, o evento não deixou a desejar em termos de qualidade: "o processo de defasagem é contínuo, pela escassez de criatividade própria dos tempos de mudanças, mas o IX Salão Nacional realizado em $\mathrm{BH}$, do ano 77, é bom, segundo os padrões da arte atual." (TRISTÃO, 1977). A argumentação de Tristão continua válida para as práticas artísticas atuais. Isso nos leva a crer que num momento em que tudo é possível como arte, a criatividade fica desorientada pela facilidade em expressar-se, sem nenhum padrão regulador, sem um critério artístico.

Mari'Stella Tristão atribuiu o grande número de cortes na categoria "gravura" a um processo de descaracterização, fruto da banalização do processo criativo da arte e da falta de domínio técnico. Seguindo na reflexão da crítica, qualquer traço passa a valer, qualquer intenção é supervalorizada, perde-se o critério, o trabalho é feito num empolgamento vazio, a arte deixa de ser arte e perde seu caráter de comunicação estética.

\footnotetext{
10 Nasceu em Uberlândia, MG, 1919 e faleceu em Belo Horizonte, 1997. Artista plástica, produtora cultural e crítica de arte do jornal Estado de Minas (196797). Formou-se em belas artes pela UFMG, BH, especializando-se em gravura, fez curso intensivo de Museologia na Faculdade de Filosofia da UFMG, BH. Foi uma das responsáveis pelo seu desligamento da Escola de Arquitetura da UFMG. Foi Presidente da AMAP, (1962-66) e assessora cultural da Reitoria da UFMG, tendo promovido inúmeras exposições. Foi assessora de arte da Secretaria do Trabalho e Cultura Popular do Estado de Minas Gerais (1964-67), período em que promoveu a $1^{\text {a }}$ Semana do Folclore e exposições de Artesanato e arte primitiva em Minas, Brasília e Rio de Janeiro. Foi coordenadora das galerias de exposições do Palácio das Artes, tendo organizado as seguintes mostras: Processo Evolutivo da Arte em Minas (1970); Semana Nacional de Vanguarda (1970) e Pré-Bienal (1971). Organizou a apresentação em Belo Horizonte do Royal Ballet de Londres e a Exposição de Artesanato Internacional (VII Semana do Folclore). Recebeu os seguintes prêmios: $1^{0}$ Prêmio de Arte Decorativa, V SMBA, BH (1941); Menção Especial de Gravura, I Bienal da Bahia, Salvador (1966); Menção Honrosa de Gravura em Metal, Salão Paulista (1963). Participou dos VIII, IX e X Salão Universitário de Arte da UEE, MG. Integrou as coletivas:Exposição Didática de Desenho e Gravura, Reitoria da UFMG (1963);Artistas Brasileiros, Lagos, Nigéria (1963); Artistas Brasileiros, Colorado, EUA (1968); Mestres Mineiros, MAP, BH (1968); Brazilian Cultural Festival, Indiana University, EUA (1967). Realizou a mostra individual, Gravura em Metal, Galeria Guignard, BH (1966). A partir de 1970 passou a se dedicar exclusivamente à crítica de arte e à produção cultural. Disponivel em: http://comarte.com/maristel.htm (Acessado em 07/06/2016 às 15:59 hs.) 11 Jayme Maurício é um dos fundadores do Museu de Arte Moderna do Rio, com Carmem Portinho, Affonso Reidy e Niomar Monis Sodré Bittencourt, motivo do seu início na crítica através do Correio da Manhã; fez parte do escritório de Lúcio Costa e Oscar Niemeyer na construção de Brasília e é fundador com Flexa Ribeiro da ESDI — Escola Superior de Desenho Industrial. Iniciou sua carreira de jornalista no Correio da Manhã, em 1950, onde escreveu sobre teatro, música, rádio, televisão, cinema e balé. (Catálogo do IX` Salão Nacional de Arte de Belo Horizonte e http://www.ims.com.br/ims/explore/artista/jayme-mauricio. Acessado em 05 maio 2016)
} 
Cuidou ainda, a comissão, em adotar rigoroso critério seletivo, especialmente no setor da gravura, considerando que essa técnica, nos últimos anos, passa por um processo de redução qualitativa e sensível descaracterização. O fato resulta do desmedido entusiasmo de iniciantes, pelas técnicas gráficas, sem o necessário suporte artístico e criativo. Os primeiros "cortes", ou as primeiras "manchas" de águas tintas, são logo considerados "trabalhos de arte" e enviados aos salões. (TRISTÃO, 1977, s/p)

Tristão também relaciona a discussão do audiovisual que teria se tornado um "modismo":

O audiovisual contou com o interesse de muitos, o que reforça nosso ponto de vista sobre o "modismo". É bonito e é a moda fazer áudio. Muitos deles são realmente bem feitos no que respeita à fotografia, cabendo restrições ao desequilíbrio das montagens quanto à integração das imagens, música, texto e voz, além da gratuidade meramente visual, sem história. (TRISTÃO, 1977, s/p)

Como é possível notar, os novos meios técnicos não foram apontados como estratégicos para uma discussão mais geral de política e não podemos afirmar se os trabalhos que foram excluídos poderiam possuir esse perfil. A discussão ainda estava associada à definição de arte contemporânea a partir da utilização de novas tecnologias, ainda emergentes. Um forte aspecto existente na década de 1970, foi a utilização de técnicas tradicionais como o desenho, mas visando a ressignificação temática ou histórica, aspecto que será tratado a seguir.

\section{História/Revisão e Invenção:}

O enfoque a uma "verdade histórica" e de sua difusão transforma-se em uma ferramenta imprescindível para o processo de dominação social. O controle da "verdade histórica" é amplamente utilizado para justificar ações violentas ou a restrição das liberdades. Tendo em vista esse cenário, alguns artistas produziram obras que tensionavam os sentidos tradicionais de "verdade" e "ficção". O trabalho de Miguel Gontijo 12 pode ser compreendido nesse sentido.

Miguel Gontijo criou a série $O$ que o uso faz ao costume: ciclo da cana de açúcar. Trata-se de um conjunto de seis aquarelas sobre papel categorizadas como desenhos de acordo com o catálogo da exposição. O artista recria o tema da cana de açúcar, mas com uma abordagem pouco convencional. Utiliza de mecanismos de re-

12 Miguel Ângelo Gontijo, nasceu em Santo Antônio do Monte, MG, 1949. Artista plástico premiado no Salão de Arte de Divinópolis, MG (1971); IX SNAPBH, MAP, BH (1977); Desegni dei Maestri, Milão, Itália (1981); II Bienal de Arte Mística, Governador Valadares, MG (1988). Participou da Mostra de Arte das Olimpíadas do Exército, Palácio das Artes, BH (1971); III Salão do Artista Plástico Mineiro, Palácio das Artes (1971); V,VII, IX, XII, XVI, XVII, XVIII SNAPBH, MAP (1973/75/77/80/84/85/86); III Salão Global de Inverno, Palácio das Artes (1975); III SNAP, Goiânia (1977); III Salão do Artista Jovem, SP (1977); III Salão Nello Nuno, Viçosa (1978); XXXIV e XXXIX Salão Paranaense, Curitiba (1978-82); I SNAP, CEC, Palácio das Artes (1978); III Salão de Arte e Cultura, Recife (1978); Salão da Cidade de Recife (1978); II SNAP, Funarte, MAM-RJ (1979); Salão de Arte da Cidade de São Paulo, Paço das Artes, SP (1979); Salão do Carnaval, Palácio das Artes (1980); II Salão do Espírito Santo, Vitória (1980); XII SAP, Goiânia (1981); III SAP, Salvador (1981); I Salão da Fundação Clóvis Salgado, Palácio das Artes (1984); Participou das seguintes coletivas: Desenhistas Mineiros, BH (1971); Centenário da Cidade de Santo Antônio do Monte (1977); Três Desenhistas Mineiros, FAOP (1979); O Desenho Mineiro, Palácio das Artes (1979); Aquarela no Brasil, Palácio das Artes (1979); Museu de Rua, MAP, BH, (itinerante, 1979); Picasso Reinterpretado, Palácio das Artes (1981); Desenhistas Mineiros, Curitiba (1982); Geração e Arte, BH Shopping, BH (1987); O Sonho de Freud, Centro Cultural UFMG, BH (1989); O Surrealismo no Brasil, Pinacoteca do Estado de São Paulo (1989); Utopias Contemporâneas, Palácio das Artes (1992); Cecília Meireles - Uma Visão Mineira, UFJF (itinerante, 1992); Improviso para Guignard, Espaço Cultural Bamerindus, BH (1996); Colóquio/Arte: Cadernos Surreais, Activités Culturelles, Paris (1996). Fez as seguintes individuais: Galeria do ICBEU, BH (1977-79); MAP, BH (1978); Fundação Cultural do Distrito Federal (1980); Galeria de Arte da Telemig, BH (1980); Galeria do Museu CalousteGulbekian, Lisboa (1980); Galeria Kuarup, BH (1981); GeorgiaUniversityArt, EUA (1981). Tem obras nos acervos do Art Institute of Chicago, EUA; MAP, Sociedade Amigas da Cultura, BH e Funarte, RJ. Disp. em: http://comartevirtual.com.br/artista/Miguel+\%26acirc\%3Bngelo+Gontijo/340. (Acessado em: 14, abril. 2016 !4:35 hs). 
presentação histórica, mas tensiona as relações entre o fato histórico e a imaginação. Apesar da utilização de ícones reconhecidos historicamente, Gontijo retira sua temporalidade ao eliminar parte dos cenários na representação. As imagens parecem flutuar em tempo e espaço. Mesmo referindo-se à história, retira parte de sua condição identitária: o espaço. Em Apogeu 1 (Figura 1), uma máquina futurista transporta uma senhora como em uma liteira. O homem que transporta a imponente senhora é parte da máquina de transporte, inclusive com um medidor de combustível acoplado à cabeça. A máquina/humana é abastecida pela cana de açúcar in natura enquanto a senhora toma uma xícara de chá. A cana de açúcar às vezes brota da cadeira onde a dama está assentada, às vezes da própria perna da figura representada, como na primeira obra com o título Decadência. O artista, apesar de usar referências históricas, constrói uma relação de uma cena irreal ou onírica.

O título é também bastante elucidativo. Como se cada obra fosse capaz de representar o "Apogeu" de uma construção narrativa. Mas como entender o Apogeu II (Figura 2)? Uma figura em trajes eclesiásticos que segura um crucifixo e tem escondido na sua indumentária uma criança indígena. Amarrada a um tronco, tendo um estandarte colocado atrás do joelho direito, uma figura está despida, prestes a ser açoitada pelo suposto padre. Entretanto, o religioso assume uma postura como se tentasse lutar contra o desejo e sua realização. $O$ apogeu estaria emblematizado pela dominação tanto simbólica quanto real. As imagens são apresentadas como se estivessem planando no ar, mesmo quando há um pelourinho explícito e algo parecido a formigas na obra em questão. As representações não estão, assim, claramente situadas sobre uma superfície definida. Na realidade, o trabalho de Gontijo é completamente insólito e nos dá margem a várias interpretações onde poderemos até nos perder, tantas são as variantes possíveis.

Nota-se uma aproximação das retratações dos pintores viajantes, tanto na técnica de ilustração como na construção da narrativa, sobrepondo imagens sequentes, contando uma história quadro a quadro. A diferença principal é que os "Pintores Viajantes" construíam um retrato real do Brasil , enquanto Gontijo aborda o tema de forma onírica, sem preocupação em manter a cena atada a uma realidade.

Pensando em termos da história do ciclo da cana de açúcar no Brasil, teremos em Decadência, a imagem de um homem de chapéu que pode nos remeter aos holandeses quando de sua retirada após anos de domínio no nordeste. Na obra intitulada Antecedentes, Gontijo mantém a atmosfera surreal, nos mostrando o colonizador entrando terra a dentro, fato sugerido pelas montanhas inseridas no círculo que emoldura a parte superior da figura do homem branco. A cana já foi plantada na terra, representada por uma figura feminina, talvez sugerindo que a mãe terra dos indígenas, os primeiros antecedentes daqui, tenha sido conspurcada e explorada pelos portugueses, de onde podemos intuir mais um elemento da dominação que nos foi imposta, talvez também aludindo à repressão do regime militar.

Em Estagnação, podemos deduzir que, após a expulsão dos holandeses e da perda do mercado do açúcar, o foco passou a ser o ouro das Minas Gerais, trazendo em Tiradentes um ícone imagético.

A segunda obra Decadência apresenta-nos uma figura nua com cana de açúcar brotando do braço esquerdo e da sua mão deste mesmo braço. Atrás da figura, uma 
nota estampa os dizeres: "caninha do reino". Gontijo pode estar indicando que, além do valor monetário alcançado pela aguardente, os índios ficaram com o cultivo da cana e com o uso da cachaça, cujo efeito pode ser notado no movimento incoerente das pernas da figura em torno de uma flecha. Com isto o artista novamente sugere um domínio que além de subjugar, deteriora o ser humano.

Talvez Gontijo nos faça refletir sobre como uma verdade imposta pode nos remeter a comportamentos e posturas direcionadas no sentido pretendido, sem opções de escolhas, em uma alusão ao regime ditatorial.

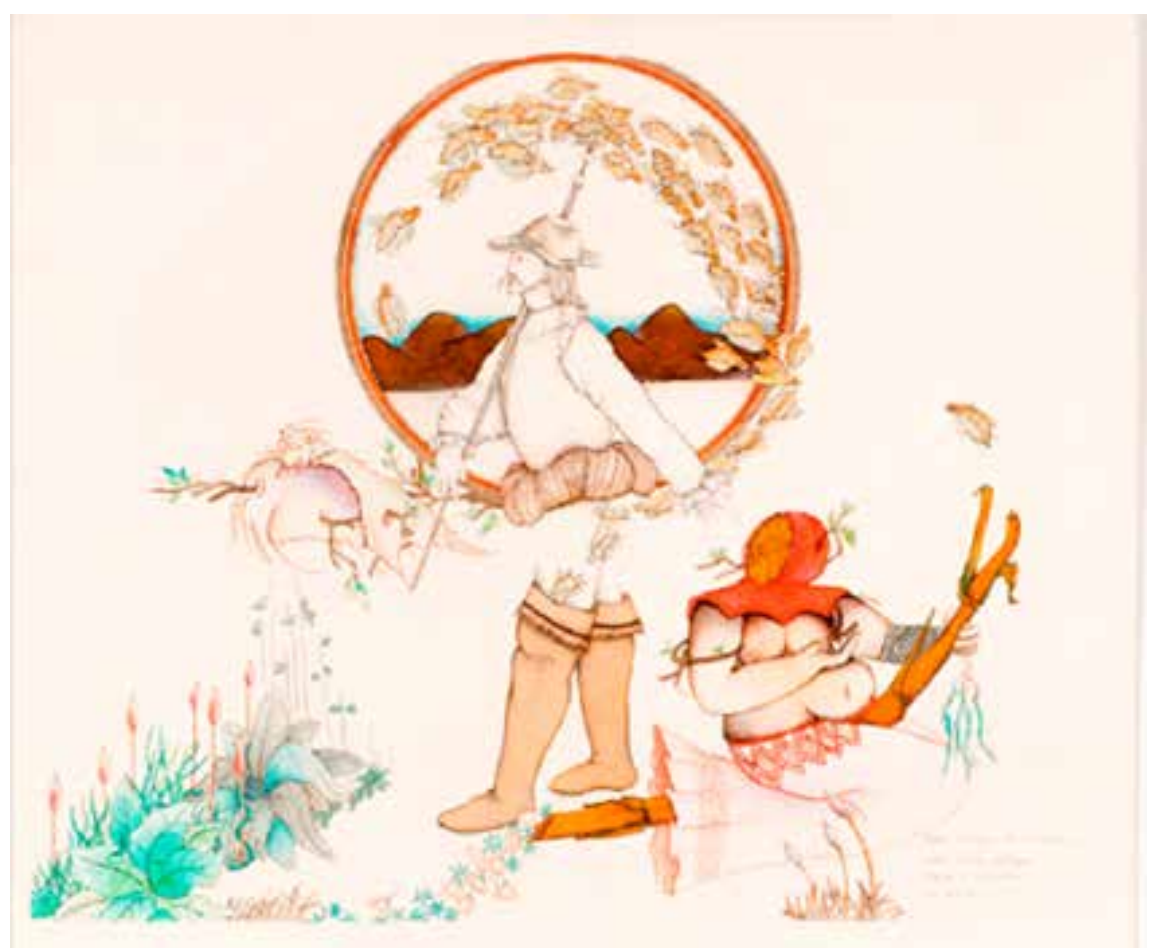

Figura 1. Miguel Ângelo Gontijo. Antecedente (da série O que o uso faz ao costume: ciclo da cana de açúcar). 1977. Aquarela sobre papel. 29 x $34,2 \mathrm{~cm}$. (Acervo do Museu de Arte da Pampulha, Belo horizonte.)

Figura 2. Miguel Ângelo Gontijo. Apogeu I (da série O que o uso faz ao costume: ciclo da cana de açúcar). 1977. Aquarela sobre papel. 29 x $34,2 \mathrm{~cm}$. (Acervo do Museu de Arte da Pampulha, Belo Horizonte.) 


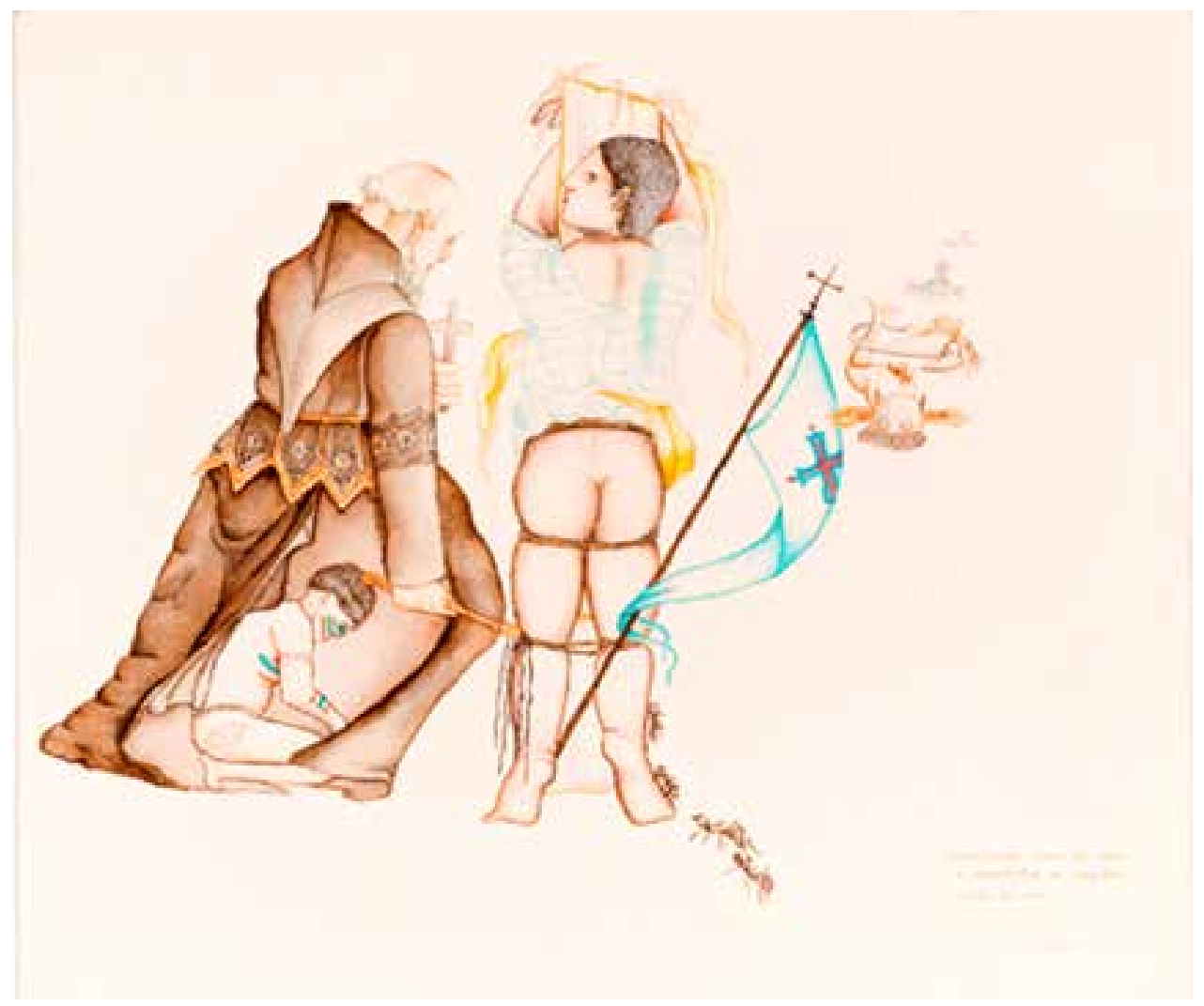

Figura 3. Miguel Ângelo Gontijo. Apogeu II (da série O que o uso faz ao costume: ciclo da cana de açúcar). 1977. Aquarela sobre papel. 29 x $34,2 \mathrm{~cm}$. (Acervo do Museu de Arte da Pampulha, Belo Horizonte.)

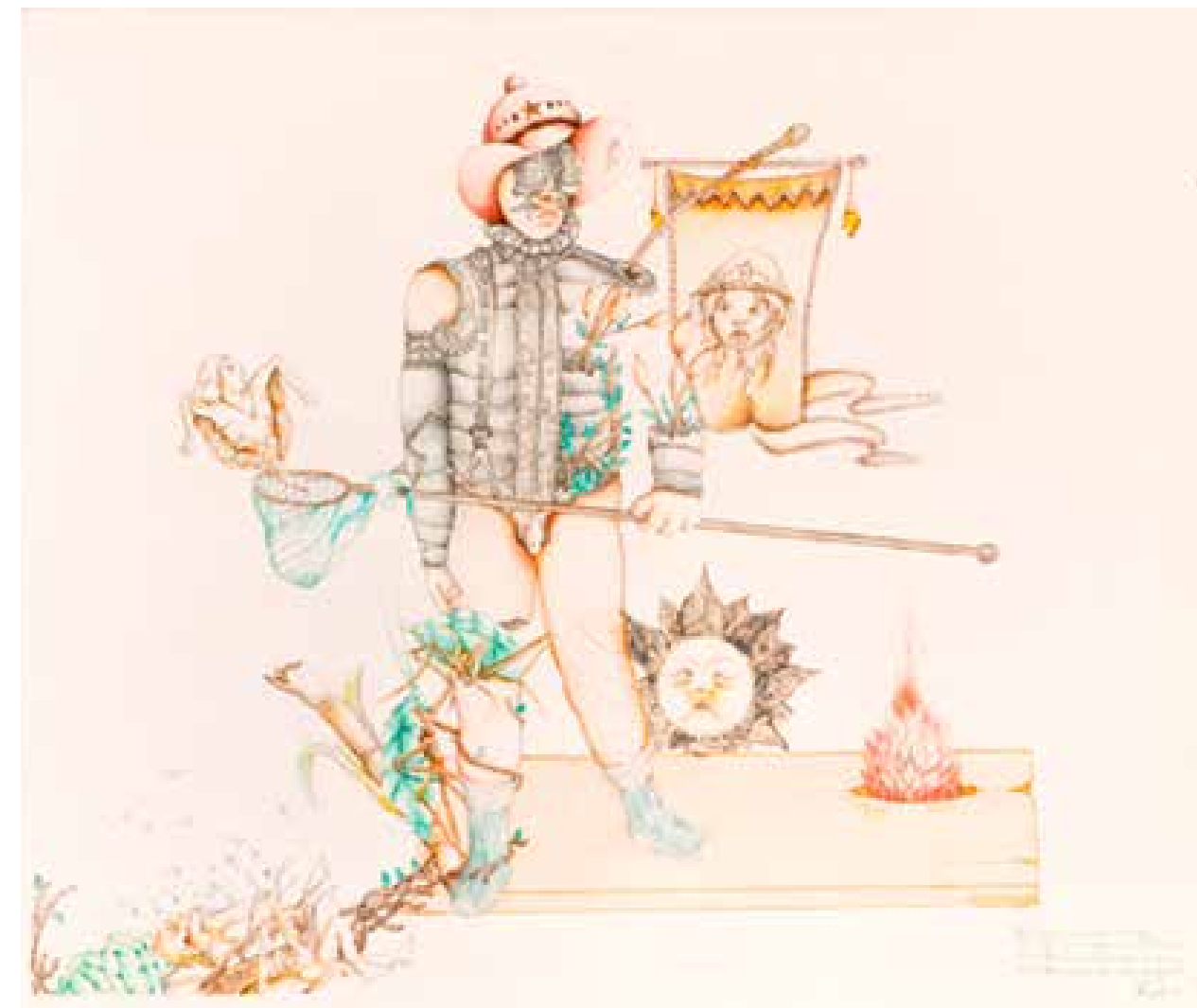

Figura 5. Miguel Ângelo Gontijo. Decadência (da série O que o uso faz ao costume: ciclo da cana de açúcar). 1977. Aquarela sobre papel. 29 x $34,2 \mathrm{~cm}$. (Acervo do Museu de Arte da Pampulha, Belo horizonte.) 


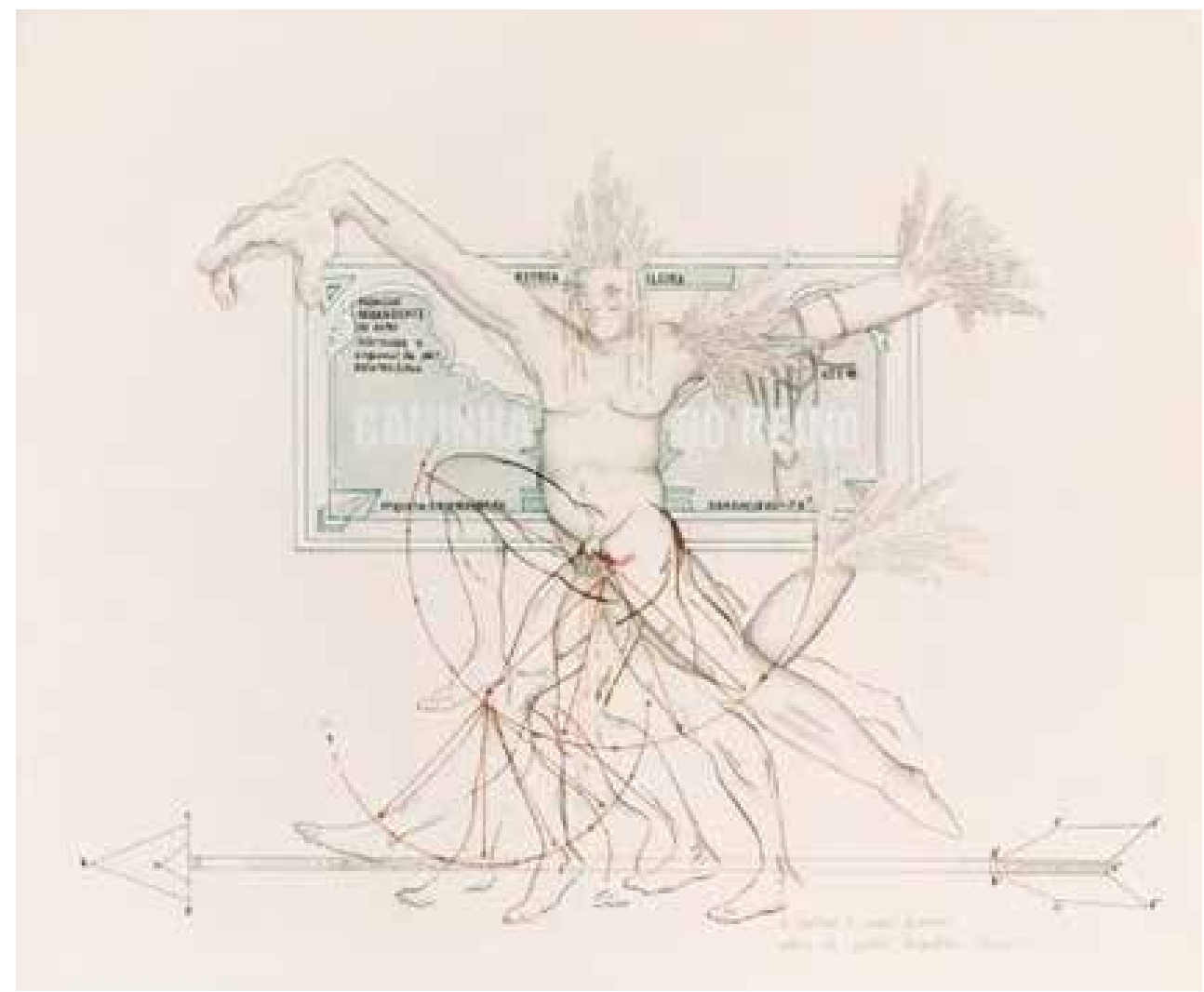

Figura 6. Miguel Ângelo Gontijo. Decadência (da série O que o uso faz ao costume: ciclo da cana de açúcar). 1977. Aquarela sobre papel. 29 x $34,2 \mathrm{~cm}$. (Acervo do Museu de Arte da Pampulha, Belo horizonte.)

\section{Conclusão}

O presente estudo visou demonstrar as complexas relações entre ambiente cultural/político e as produções artísticas. Muitos estudos ainda persistem negando as relações de suficiência das produções artísticas e como os artistas, parafraseando G. C. Argan, respondem questões sociais e históricas como criador, assim como filósofos as enfrentam como filósofos e políticos como um problema político. Muitas vezes, espera-se encontrar uma relação direta com o contexto, o que pode reduzir a complexidade analítica das produções artísticas.

A obra de Miguel Gontijo é um importante exemplo de uma resposta artística. Ao utilizar de um meio tradicional, a aquarela, rejeita os "novos meios" que estavam sendo supervalorizados na década de 1970. Dialoga com uma estética dos artistas viajantes, mas subverte a constituição histórica com uma poética surrealista.

\section{Referências}

ALVIM, C. "O Salão e seus Desencontros". Artes Visuais. Estado de Minas. Belo Horizonte, Minas Gerais. Sem página. 16 de dez. de 1973.

AYALA, W. "Desenho no salão". Artes Plásticas. Jornal do Brasil. Rio de Janeiro, RJ. Sem página. 6 de dez. de 1973. 
AYALA, W. "Prêmios do salão mineiro", Artes Plásticas. Jornal do Brasil, Rio de Janeiro. Sem página. 14 de dez. de 1973.

DUARTE, Paulo Sergio. Anos 70 - A arte além da retina. In: INSTITUTO CULTURAL ITAU. Anos 70: trajetórias. São Paulo: Itaú Cultural: Iluminuras, 2005, p. 133-145.

Entrevista/depoimento de Jayme Maurício. Catálogo do IX Salão Nacional de Arte de Belo Horizonte. Belo Horizonte, Minas Gerais. Sem página.

FREITAS, Arthur. Arte Guerrilha: Vanguarda e Conceitualismo no Brasil. São Paulo: EDUSP, 2013.

FREITAS, Artur. Poéticas políticas: as artes plásticas entre o golpe de 64 e o Al-5.

HISTÓRIA: Questões \& Debates. Curitiba, v.21, n.40, jan./jun.2004, p.59-90.

MOTA, M. "Os Erros de um Salão de Arte". Homem e mulher. Diário da Tarde, Belo Horizonte, Minas Gerais. Sem página, 21 de dez. de 1970. MOTA, M. "Salão \& Resultado". Artes. Diário da Tarde. Belo Horizonte, Minas Gerais, Sem página, 04 de dez. de 1973.

OLIVEIRA, Emerson Dionísio Gomes de. A arte de julgar: apontamentos sobre os júris de salões brasileiros nos anos de 1960. In: COLÓQUIO DO COMITÊ BRASILEIRO DE HISTÓRIA DA ARTE, 31, 2011, Campinas. Anais do XXXI Colóquio do Comitê de História da Arte. Campinas: UNICAMP, 2011.

RIDENTI, Marcelo. O Fantasma da Revolução Brasileira. São Paulo: Editora da Universidade Estadual Paulista, 1993. (Referência de Marcelo Ridenti, 1993, na p. 4 deste texto)

RIDENTI, Marcelo. Em busca do povo brasileiro. Rio de Janeiro: Record, 2000.

SOARES, Teresinha. O Circo e a Montanha. Estado de Minas. 11 de dezembro de 1973. Belo Horizonte - MG.

TRISTÃO, M. "A arte e a arte deste nosso Salão". Estado de Minas, Belo Horizonte, Minas Gerais. Sem página, 10 de dez. de 1977. 